\title{
Youth earnings and labour market volatility in Europe ${ }^{1}$
}

\author{
Sara Ayllón ${ }^{2}$ \\ Department of Economics \\ Universitat de Girona and EQUALITAS \\ Xavier Ramos ${ }^{3}$ \\ Department of Applied Economics \\ Universitat Autònoma de Barcelona, IZA and EQUALITAS
}

We provide new evidence on earnings volatility and labour market volatility, which also includes flows into and out of employment, of young workers across Europe during the Great Recession, and examine the institutional factors that may shape these flows. Using EU-SILC data, we document large disparities in volatility levels and trends across European countries. As expected, the Great Recession increased volatility among Europe's youth, offsetting the falling trend observed over the last years of economic prosperity. Larger unemployment benefits and more stringent employment protection legislation are related to lower earnings and labour market volatility.

Keywords: Earnings volatility, Labour market volatility, Youth, Labour flows, Labour market institutions, Europe, Great Recession

JEL classification: J41, E24, C46, C23

\footnotetext{
1 This paper has received funding from the European Union's Horizon 2020 Research and Innovation Programme under grant agreement no. 649395, project title: NEGOTIATE - Overcoming early job-insecurity in Europe. Both authors also acknowledge financial support from the projects ECO2013-46516-C4-1-R, ECO2016-76506-C4-4-R and 2014-SGR-1279. We are grateful to participants at the Negotiate Meeting in Athens (September 2015) and at EALE in Ghent (September 2016) for their useful comments. Any errors or misinterpretations are our own.

${ }^{2}$ Corresponding author. Address: C/ Universitat de Girona, 10, 17003 Girona, Spain. Tel. (+34) 972418779. E-mail: sara.ayllon@udg.edu

3 Address: Facultat d'Economia i Empresa, Edifici B, 08193 Bellaterra, Spain. Tel: (+34) 935812686. E-mail: xavi.ramos@uab.cat
}

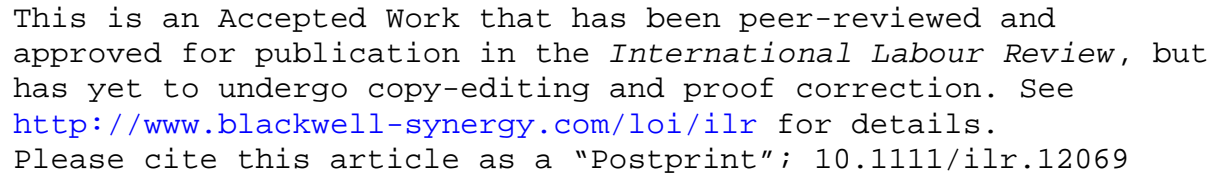




\section{Introduction}

Individuals dislike instability, as it hampers important economic outcomes such as education (Kodde, 1986; Snow and Warren, 1990), health (Caroli and Godard, 2016), consumption and savings behaviour (Guiso and Jappelli, 1992; Meghir and Pistaferri, 2011), housing demand (Haurin, 1991), divorce (Becker et al., 1977), and well-being in general (Clark et al., 2008). Economic instability is particularly relevant for youth when it comes to emancipation (Becker et al., 2010; Matsudaira, 2016), fertility (Del Bono et al., 2012, 2015) or marriage (De la Rica, 2005). This paper provides new evidence on economic instability, as measured by earnings and labour market volatility across Europe over the period of the Great Recession for the population group hardest hit by the severe economic downturn: the youth.

There is a growing corpus of literature on the analysis of earnings volatility (Ziliak et al., 2011; Venn, 2011; Cappellari and Jenkins, 2014). Most of the studies have been devoted to analysis of prime-aged men (Baker and Solon, 2003; Daly and Valletta, 2008; Shin and Solon, 2011; Shin, 2012) and, only more recently, also women (Dynan et al., 2012; Cappellari and Jenkins, 2014). However, there is little evidence on earnings instability among young people, for whom economic instability is likely to be more pronounced than for other age groups. It is also likely to condition life decisions and investments. Previous evidence focuses mostly on country studies and stops right when the Great Recession is about to begin. Our contribution complements previous evidence in two important respects: first, we provide a consistent analysis across 28 European countries; and second, our analysis covers the period both before and after the major economic turmoil of the Great Recession. Venn (2011) studies earnings instability for a large set (though smaller than ours) of European countries, also using data from the EU-SILC. However, like all previous studies, he only covers the pre-crisis period and uses a rather crude measure of volatility. Sologon and O'Donoghue (2014) examine earnings volatility for a smaller set of European countries in the 1990s. They also explore the links between labour market institutions and earnings volatility; but, like most previous studies, they confine analysis to prime-age men.

Following recent literature, the measure of instability we use copes with zero earnings, which means that we do not limit our analysis to strictly positive earnings, but also take due account of entries to and exits from employment. This measure is also especially suitable for the data we use - the European Union - Statistics on Income and Living Conditions (EU-SILC) - which has a short panel component, where individuals are observed in four consecutive years, at most.

Our findings show large disparities in youth earnings, and especially labour market volatility levels and trends across European countries, which makes it difficult to group the countries into meaningful clusters. As expected, the Great Recession increased volatility among Europe's youth, offsetting the falling trend observed over the last years of economic prosperity. With few exceptions, volatility is found not to differ across gender, age or perhaps more surprisingly - education.

Institutions are a salient feature of European labour markets and shape important labour market outcomes. When we look at the relationship between labour market institutions and volatility, we find that more generous unemployment benefits and stricter employment protection legislation are related to reduced (earnings and labour market) volatility. This finding is consistent with these two institutions increasing the quality of job matches and thus reducing volatility.

The paper is organized as follows. Section 2 describes our data. Section 3 sets out our 
measure of volatility. Section 4 presents the results for earnings and labour market volatility trends across all European countries. A variance decomposition exercise contributes to our understanding of what accounts for the trends observed. Section 5 links volatility and labour market institutions. Finally, there is a conclusion and discussion of avenues for future research.

\section{Data}

We use data from all the waves available for the EU-SILC in its longitudinal form, at the time of writing. The EU-SILC has the advantage of collecting detailed information on individual and household earnings, as well as socio-economic and demographic characteristics. Moreover, data is comparable across the participating European countries. In most, though, the longitudinal component only follows individuals for four consecutive waves, which implies that each year $25 \%$ of the sample is replaced by a new rotational group. This means that we will be observing changes on (at most) three occasions for each individual. Our pooled dataset has been constructed by taking the information from the last file in which a given rotational group appears (Iacovou and Lynn, 2013). This is important to guarantee that changes in the way information is collected across waves do not affect our results: the same longitudinal methodology is applied to all individual observations that appear in a file.

The period under analysis starts in 2004 and ends in 2013. We obtain results for 28. The sample contains 169,385 individual observations. The smallest sample is found in Iceland, with 2,175 observations; and the largest in Italy, with 14,450.

Our results are based on changes in individual-level earnings between two consecutive years $t-1$ and $t$. Our sample includes young people aged 17 to 29 , either employed or not employed. We exclude: (i) individuals who are either 17 at $t$ or 29 at $t-1$ ; (ii) individuals with missing information on labour market status at $t-1$ or at $t$; and (iii) full-time students at either $t-1$ or $t .{ }^{1}$

Non-random attrition may bias our measures of volatility. Notwithstanding this, as we use volatility measures based on only two consecutive years of data, the effects of attrition are much muted - as compared, say, to other measures based on longer sequences of panel data. Also note that since our volatility measure, described in Section 3, involves differentiating the variable of interest (i.e. earnings), the effect of attrition will be attenuated if we can assume that the probability of attrition is unobserved and time invariant (Ziliak et al., 2011). ${ }^{2}$ Measurement error may introduce spurious volatility into our estimates, biasing them upwards (Cappellari and Jenkins, 2014). However, using (latent class) models to correct for measurement error, as in Breen and Moisio (2004), is beyond the scope of the paper. Other limitations of our study derive from the actual design of the EU-SILC, which has come in for some criticism. There are significant differences between register countries, survey countries and proxy countries that can affect our cross-country comparative analysis (Krell et al., 2017) either because of the different treatment that the income variables have received or because of the tracking rules that establish who is interviewed when a household splits (Iacovou and Lynn, 2013), among many other factors. Unfortunately, there is little that researchers can do ex post to overcome these issues.

Our measure of earnings is 'gross employee cash or near cash income'. Earnings from second and third jobs are included in the original income variable by Eurostat and cannot be disaggregated. However, we regard this as an advantage, given that taking additional jobs may be an important response to the threat of losing a better-paying job in bad 
economic times. All the nominal amounts have been converted to 2005 prices, using the annual data of the Harmonised Index of Consumer Prices (HICP) made available to researchers on the Eurostat web page. As income in the EU-SILC dataset is collected with reference to the previous calendar year, the HICP has been used accordingly. Importantly, the income variable is in gross amounts for the great majority of countries and waves. However, note that in the cases of Italy, Portugal and Greece for the years 2004 to 2006, Latvia for 2005 and 2006 and France for 2004, the variable is only available in net amounts. We have decided to use this information, but we make sure that we do not calculate transitions for the same individual from net to gross amounts. This explains why we have a break in the time series in the aforementioned countries (see graphs). Finally, in the case of Spain, in 2004 and 2005, the income information is given either in gross amounts, net or both. Again, we derive results for both years, but only for those individuals for whom we can calculate transitions either in net or in gross amounts. Thus, we disregard the observations when we can only calculate transitions from net to gross or from gross to net income. A comparison of levels and trends between volatility measured with gross and with net amounts in order to account for the importance of the automatic stabilization effects of the tax and transfer system during the Great Recession would be an interesting exercise. However, researchers have no access to both income distributions for all countries during the whole period under analysis.

\section{Methodology}

Adopting the terminology used in Cappellari and Jenkins (2014), in this paper we analyse 'earnings volatility' and 'labour market volatility'. Earnings volatility studies the instability of earnings for young people who have positive incomes at the two time points under analysis, so it captures changes in the conditions enjoyed while working. The labour market volatility measure covers all potential workers, including those with zero earnings; thus it summarizes not only changes in wages, but also transitions into and out of employment. There are no individuals with negative earnings in our sample.

Our principal measure of volatility among young people is the standard deviation of the arc percentage change in individual earnings between $t-1$ and $t$, as proposed by Dynan et al. (2012). That is,

$$
l=\sqrt{\operatorname{Var}\left[100 \times \frac{y_{i t}-y_{i t-1}}{\bar{y}_{i}}\right]}
$$

where $y_{i t}$ is earnings for person $i$ at time $t$ and $\bar{y}_{i}$ is the mean across the matched pair of years. The main advantage of this measure is that it can be computed even if earnings are zero in one of the two years - thus, it allows for the measurement of labour market volatility. At the individual level, it is bounded between $-200 \%$ and $+200 \%$ and equals zero in those cases when a young person is out of employment at $t-1$ and $t$. Earnings change for those who move into work is $+200 \%$, while for those who move out of work it is $-200 \%$. At the aggregate level, $l$ is bounded below by zero, when earnings changes are exactly the same for every individual. Otherwise, the larger the dispersion, the greater the measure of volatility. We employ the standard deviation for the whole descriptive analysis (and not the 
variance), except for Section 4.2, where we undertake a variance decomposition exercise.

Unlike other methods that have been used to estimate the instability of earnings, such as the variance component approach developed after the pioneering contribution by Lillard and Willis (1978), the method we employ does not allow us to distinguish between transitory and permanent earnings changes. However, several authors have claimed that such a distinction may not be that useful, since both type of change are likely to influence the welfare of an individual (Shin and Solon, 2008; Dynan et al., 2012). Shin and Solon (2011) argue that parametric models of earnings dynamics that decompose earnings inequality into permanent and transitory components are sensitive to arbitrary variations in model specification: 'We therefore sympathize with the inclination of several other researchers ... to eschew complex earnings dynamics models and focus instead on transparently simple statistics that might be reasonable indexes of earnings volatility under a wide range of data-generating processes' (p. 975). We refer the interested reader to Shin and Solon (2011) for a discussion of the disadvantages of using complex decomposing models and arguments that advocate the use of simpler measures (especially if data is close in time, like year to year).

Indeed, earnings volatility measures based on dispersion in year-to-year earnings capture permanent and transitory shocks; but this is appropriate when the object of the research is to learn about possible increases in earnings risk. Another advantage of the method we use in this paper is that it is less data intensive. On the negative side, this measure of volatility based on year-to-year changes is more subject to measurement error.

\section{Results}

\subsection{Youth volatility trends}

Figure 1 shows the trends in earnings volatility and labour market volatility for youth aged 17-29 across Europe. It is important to remember at this point that the earnings volatility measure does not include individuals with zero earnings at either of the time points, while labour market volatility also takes into account individuals who are not employed and therefore do not receive earnings from the labour market. Graphs contain confidence intervals, computed using bootstrap standard errors with 1,000 replications. A vertical line has been drawn in 2008 to ease comparison between the period before and after the outbreak of the Great Recession. The slump did not start at the same time in all countries, but 2008 is possibly the year when the crisis hit most of Europe hardest.

We start examining the volatility estimates of Figure 1 by classifying the countries into low-, medium- and high-volatility countries, according to the distance between the country average volatility level over the sample period, $\bar{l}_{i}$, and the overall average volatility

level across all countries and over all years, $\bar{l}$. In particular, we consider that a country displays 'low volatility' when $\bar{l}_{i}<\bar{l}-0.5 \sigma_{\bar{l}}$, where $\sigma_{\bar{l}}$ is the standard deviation of overall volatility. Likewise, countries will be said to display medium levels of volatility when $\bar{l}-0.5 \sigma_{\bar{l}}<\bar{l}_{i}<\bar{l}+0.5 \sigma_{\bar{l}}$, and high levels of volatility when $\bar{l}_{i}>\bar{l}+0.5 \sigma_{\bar{l}}$.

The countries found to display 'low earnings volatility' are the Czech Republic, Greece, Luxembourg, Malta, the Netherlands, Romania, Slovakia and the United Kingdom. Actually, Romania in 2012 displays the lowest estimate of earnings volatility of all countries 
and years $(l=26)$. The group with medium earnings volatility also includes a great variety of countries: Belgium, Cyprus, Denmark, Hungary, Ireland, Iceland, Italy, Poland, Portugal and Slovenia. Finally, high earnings volatility levels are found in Austria, Bulgaria, Estonia, Finland, France, Latvia, Lithuania, Norway, Spain and Sweden. The highest earnings volatility $(l=70)$ is found in Latvia in 2011. The composition of the different groups makes it difficult to come up with a variable, such as the region or welfare regime, that could identify the three clusters of countries - perhaps the only exception are the Scandinavian countries, as they all belong to the medium- or high-volatility groups.

Over time, we find great heterogeneity in trends. Youth earnings volatility increased by more than 20\% between 2008 and 2013 in Iceland, Latvia, Malta and Spain. In contrast, earnings volatility decreased in eight countries, particularly in Austria, Belgium and Poland, where it fell by more than 10\%. Note that the value for 2013 is not available for all countries analysed. A simple visual inspection of Figure 1 shows that year-on-year changes in earnings volatility are not statistically significant for some countries and years (but note that earnings volatility increases over the recession period in many countries). Actually, multivariate analysis in Section 5 shows volatility increasing with the Great Recession. Furthermore, note that most countries remain in the same low, medium or high earnings volatility group when the analysis is carried out by time period (before and after 2008) - the only exceptions being Cyprus, Greece and Portugal, which move from the low to the medium group; Slovakia, which goes from the medium to the low group; and Hungary, Poland and Slovenia, which change from the high to the medium group.

Figure 1: Earnings and labour market volatility in Europe for young people aged 17-29, 2005-2013

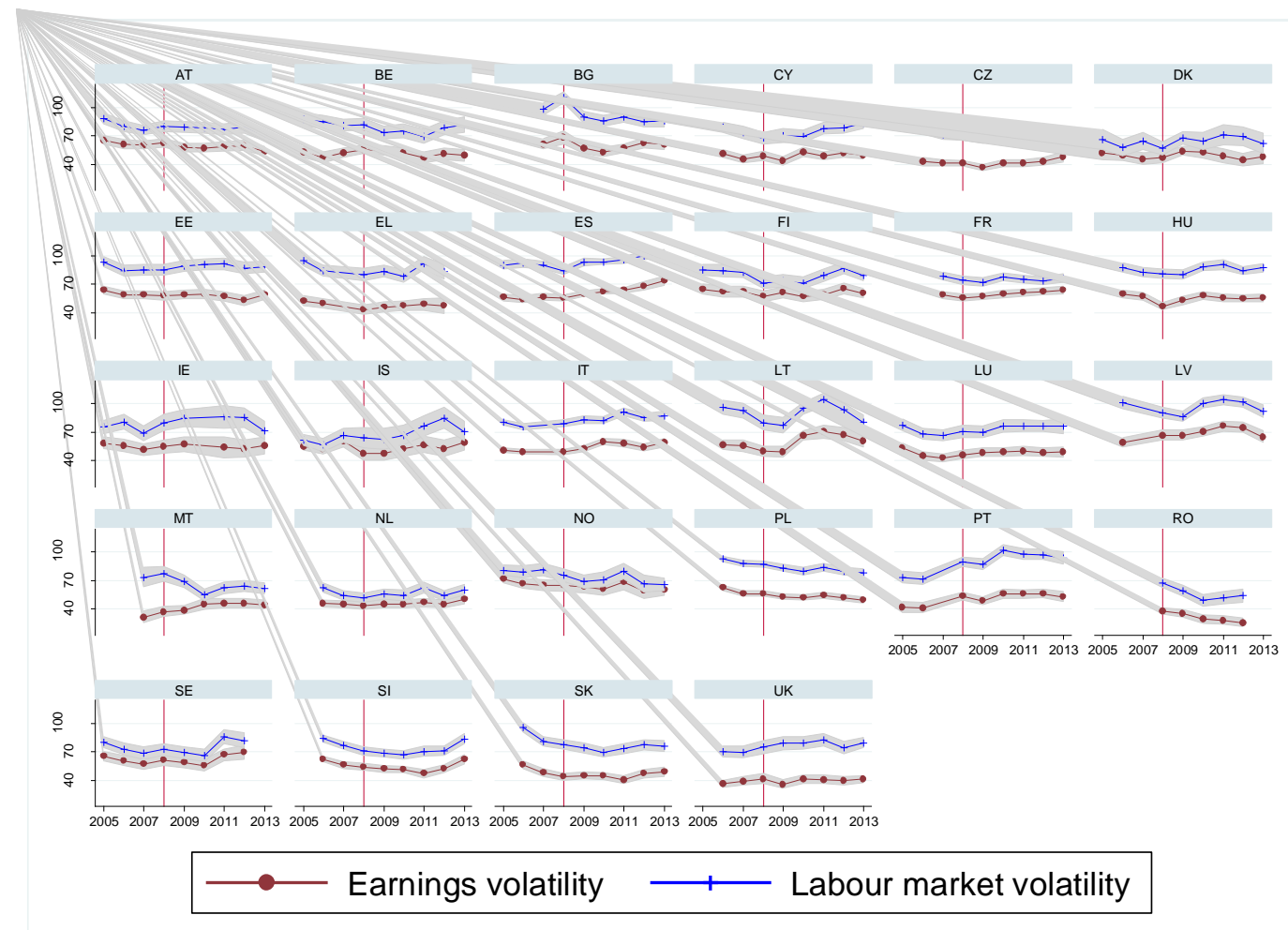


Source: Own calculations based on the EU-SILC, 2005-2013. Confidence intervals have been calculated using bootstrap standard errors with 1,000 replications.

A somewhat different picture emerges if we turn to labour market volatility: many countries do not belong to the same (low/middle/high) volatility group. In the low labour market volatility group we still find the Czech Republic, Malta, the Netherlands and Romania, but we need to add Denmark and Iceland. The majority of countries are found in the medium labour market volatility group; while in the high-volatility group we have Bulgaria, Estonia, Hungary, Latvia, Lithuania and the Southern European countries of Greece, Spain and Portugal. Therefore, it is again difficult to define clear clusters of countries - except once again for the Scandinavian countries, which are all located in the low- and medium-volatility group, and the Southern European countries, which are either in the medium or the high group.

As for the evolution of labour market volatility, we observe large increases of above 20\% between 2008 and 2013 in Spain and Cyprus, and relatively high increases also in the Netherlands (17\%) and Slovenia (18\%). A fall of larger than $10 \%$ is found in Austria, Bulgaria, Ireland, Malta, Norway and Poland. With the exception of only a few countries (e.g. Spain, Lithuania, Poland, Portugal and Slovakia), changes observed between the first and the last sample year are not large enough for us to speak of a significant increase or decrease in labour market volatility across Europe. In the case of labour market volatility, the number of countries that change volatility category is larger than in the case of earnings when we do the analysis by period. Belgium, Finland, Poland and Slovakia move from high to medium; Italy from medium to high; the Czech Republic, Malta, Norway and Slovenia from medium to low; and Luxembourg and the United Kingdom from low to medium. However, once again, multivariate analysis in Section 5 shows U-shape year effects over the period with a minimum between 2008 and 2009.

Earnings and labour market volatility trends are close to each other in Northern European countries and in the Netherlands, indicating that much of the labour market volatility can be accounted for by earnings volatility, rather than by entries into and exits from the labour market. By contrast, where both volatility measures are far apart, as in Greece, Spain and Portugal, our estimates suggest that labour market volatility is much more affected by worker turnover, and earnings changes play a less important role. We take a closer look at the importance of earnings changes, separations and accessions in explaining labour market volatility in Section 4.2 below.

We also analyse earnings and labour market volatility trends when accounting for certain socio-demographic characteristics, in particular, gender, age and educational attainment. All figures are available from the authors on request. Trends by gender indicate that there is no difference between boys and girls, as the two curves that represent the genders clearly overlap for the majority of countries analysed; therefore, the rest of our analysis considers males and females jointly. We also consider earnings and labour market volatility by distinguishing between younger youth (17-23) and older youth (24-29). Again, the curves overlap for most years and countries, indicating that overall younger and older youth experience similar levels of volatility. By highest educational level attained (ISCED), we also find an overlap between the curve that shows the volatility measure for individuals with tertiary education and the rest. Only in Finland, France, Spain and the United Kingdom can 
we observe some years where labour market volatility is higher for those with primary or secondary education than for those with a university degree.

\subsection{A decomposition exercise}

The better to understand the volatility trends observed, we now decompose our measure of labour market volatility. As explained in Cappellari and Jenkins (2014), since we have mutually exclusive groups in the labour market (employed or non-employed at different points in time), we can compute the variance of the arc percentage change as the weighted sum of the 'within' and 'between' group variances. The 'within-group' variance is the sum of the variance of each group, weighted by the population share of each group. In total, there are four groups, depending on whether individuals have positive earnings at $t-1$ and at $t$ ( $P_{11}$ ), positive earnings only at $t-1\left(P_{10}\right)$, positive earnings only at $t\left(P_{01}\right)$ or no earnings from the labour market in either of the periods $\left(P_{00}\right)$. The 'between-group' variance is the variance of a counterfactual distribution, where each individual is attributed the mean value of her group.

Using the same notation as in Cappellari and Jenkins (2014), the population mean arc percentage earnings change, $M$, can be decomposed as follows:

$$
M=M_{11} P_{11}+M_{10} P_{10}+M_{01} P_{01}+M_{00} P_{00}
$$

where $M_{00}=0, M_{01}=+200, M_{10}=-200$ and $P_{11}, P_{01}, P_{10}$ and $P_{00}$ are the population shares that add up to 1 . Thus $M$ can be written as

$$
M=M_{11} P_{11}+200\left(P_{10}-P_{01}\right)
$$

Moreover, since $V_{10}=V_{01}=V_{00}=0$, the 'within-group' variance is equal to the variance in the always-employed group, $V_{11}$, weighted by its population share $P_{11}$. Therefore, the overall variance $\left(V=l^{2}\right)$ can be computed as the sum of the within-group variance and the four components of the between-group variance,

$$
V=l^{2}=V_{11} P_{11}+P_{00} M^{2}+P_{01}(200-M)^{2}+P_{10}(200+M)^{2}+P_{11}\left(M_{11}-M\right)^{2} \text {. }
$$

Figure 2 shows for each country the importance of the different components of the labour market volatility variance over time. Blue bars show the percentage of the within-group variance $\left(V_{11} P_{11}\right)$ over the total variance, while green and yellow bars show the components due to entries into $\left(P_{01}(200-M)^{2}\right)$ and exits from the labour market ( $\left.P_{10}(200+M)^{2}\right)$, respectively. The other two variance components, $P_{00} M^{2}$ and $P_{11}\left(M_{11}-M\right)^{2}$, drawn in red and in grey, represent such a small part of the total labour market variance in most countries that they can hardly be seen in the graphs, and are thus not commented on any further.

Figure 2 shows great cross-country variability in the share of earnings volatility variance relative to overall labour market volatility variance. In Northern Europe, earnings volatility explains the largest share of the labour market volatility variance - the maximum being Iceland in 2006, where $85 \%$ of the total variance is accounted for by changes in 
earnings. This means that in these countries, as well as in Slovenia and the Netherlands, young people are more likely to face changes in the wages they receive from the labour market than in the opportunities they are given to enter the labour market.

However, in the Southern European countries and in the United Kingdom and Romania, earnings volatility variance plays the least significant role - less than $30 \%$ of the variance is due to earnings changes - which implies that entries to and exits from the labour market are more important. For example, entries and exits represented $41 \%$ and $31 \%$, respectively, of the total volatility variance in Spain in 2005. Thus, even in a period of economic growth, the Spanish youth labour market is characterized by great worker turnover. Greece, Portugal, Italy and Belgium show similar patterns.

Figure 2: Decomposition of labour market volatility (within and between variances), individuals aged 17-29, 2005-2013

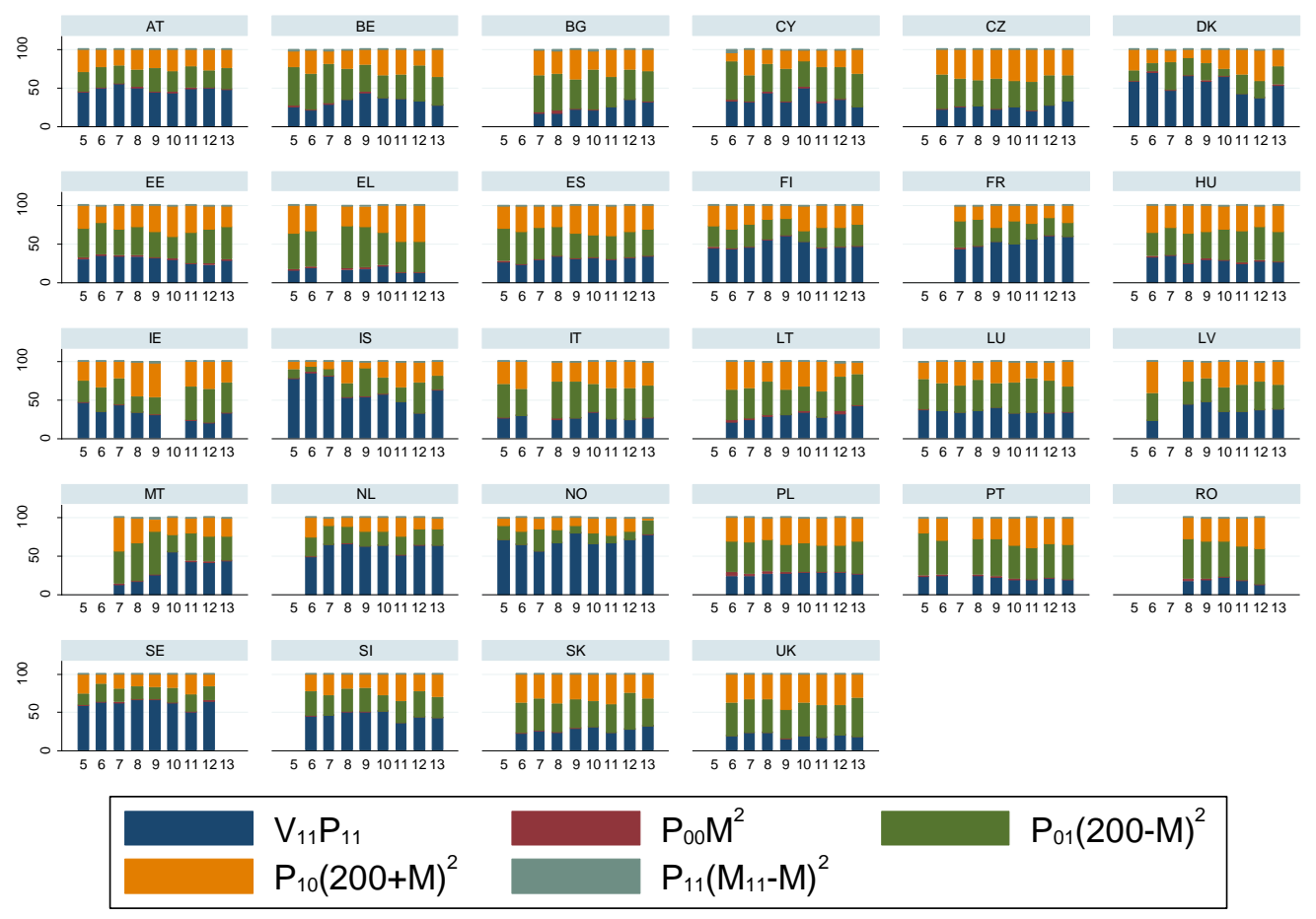

Source: Own calculations based on the EU-SILC, 2005-2013.

With the outbreak of the Great Recession, the share of overall volatility variance accounted for by transitions into and out of the labour market components increases in many countries. In order to illustrate these changes, Figure 3 shows trends in the absolute value of the volatility and of the three main components. In particular, note the parallelism between the yellow line representing the 'exits' component $\left(P_{10}(200+M)^{2}\right)$ and the blue line for the total volatility variance $(V)$ in Greece, Norway and Portugal. Again, taking Spain as an example, we find that $26 \%$ of total volatility variance is accounted for by exits in 2008 , while 
the same figure is $39 \%$ in 2011, when the consequences of the economic crisis were still much in evidence. For Greece, the corresponding figures are $28 \%$ and $46 \%$.

The increase in the importance of the variance component due to exits is offset by decreases either in the component due to entries or in the component due to earnings changes. For instance, in Finland the 'exits' component increased its share from $17 \%$ to $28 \%$ between 2008 and 2012; the 'earnings change' component decreased its share from 56\% to 46\%; and the 'entries' component remained constant. Results show similar patterns for Denmark and Sweden. Unlike Finland, the increase in the 'exits' component in Greece was offset by a decrease in the 'entries' component from $56 \%$ to $41 \%$, while earnings changes again remained constant.

Figure 3: Labour market volatility variance components trends, 2005-2013

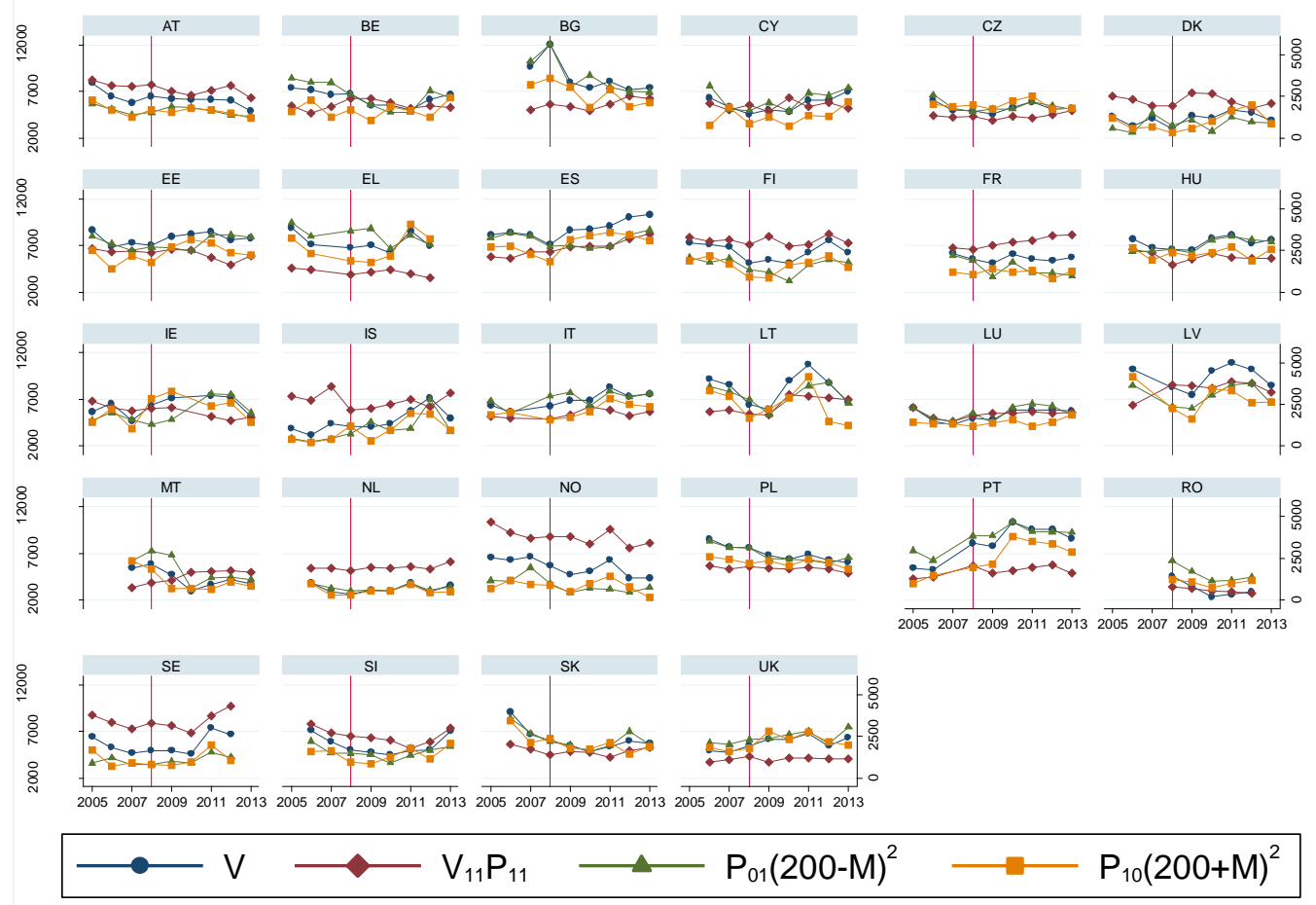

Source: Own calculations based on the EU-SILC, 2005-2013. The right axis refers to overall volatility, while the left axis refers to the components. 
Figure 4: Percentage of individuals according to their employment status at $t-1$ and $t$, 2005-2013

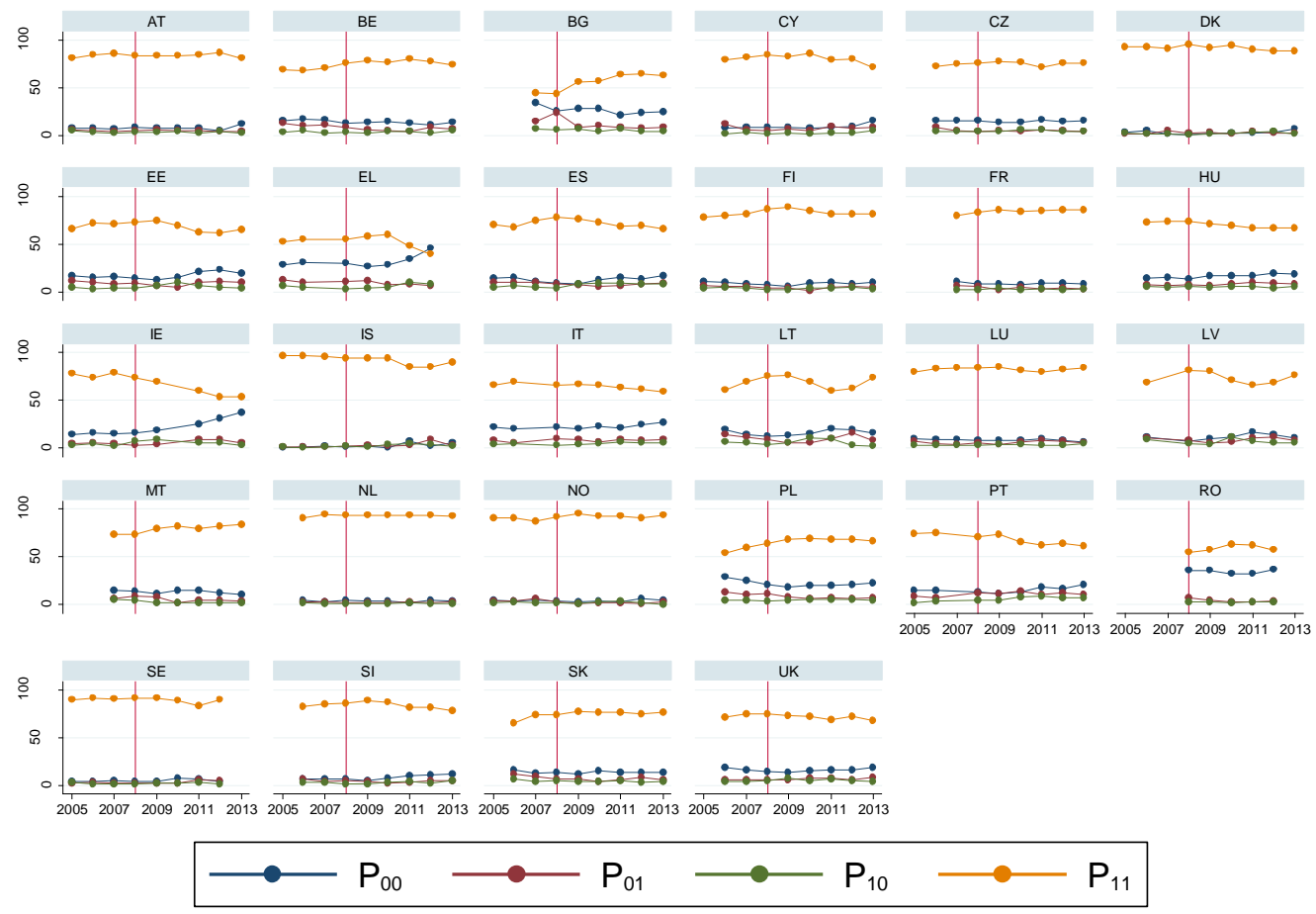

Source: Own calculations based on the EU-SILC, 2005-2013.

The relative size of the four groups $\left(P_{11}, P_{10}, P_{01}, P_{00}\right)$ are important to understand the trends in the volatility components shown in Figure 2. To gain a better understanding of these trends, Figure 4 shows the evolution of the shares of the four population subgroups. First, note the large disparity across countries in population shares of group $P_{11}$. For instance, at the beginning of the period, $P_{11}$ is as high as $90 \%$ in the Northern European countries (except Finland), but as low as $53 \%$ in Greece. This helps us understand why earnings volatility is the main driver of labour market volatility in Northern Europe, and why its importance is so low in Southern Europe, Romania and Poland. Second, the percentage of individuals entering or exiting the labour market (and thus contributing to labour market volatility) is rather low even in countries with sky-high unemployment rates. The percentage of individuals exiting the labour market reached the highest values around 2011 in Spain, Greece and the three Baltic countries (with figures between 9\% and 11\%). This brings us to a third piece of evidence: those countries hardest hit by the Great Recession show a high percentage of individuals in the group $P_{00}$ - even before the economic crisis. This result helps us to understand why we do not find much larger labour market volatility: young people who are out of the labour market remain so for long periods of time, and therefore do not contribute to measured volatility. 


\section{Accounting for volatility}

This section examines the institutional factors that may shape both earnings and labour market volatility. First, we draw on existing theoretical work and empirical evidence to briefly outline how relevant institutions are supposed to influence volatility; then we report our findings on the relationship between estimated labour market and earnings volatility and labour market institutions. In our empirical analysis, we consider the following institutions: unemployment insurance (through its replacement rates), trade union (density), active labour market policies (expenditure as a percentage of GDP), employment protection legislation (EPL) (using two indices of strictness of EPL for temporary and permanent contracts), minimum wages (relative to the median wages of full-time workers) and openness to trade (by means of a globalization index). In addition, we consider the percentage of youth aged 15-29 not in employment, education or training (NEET) - as a proxy for the quality of the educational system and school drop-outs (for which there is no consistent information covering all our sample countries over our sample period) - the unemployment rate, and GDP level and growth.

\subsection{How should we expect institutions to matter?}

Since the main difference between our two measures of labour market and earnings volatility lies in the entries to and exits from employment, we first examine the expected impact of the six institutions mentioned above on worker turnover; then we discuss the possible effects on the variability of individual earnings growth.

\subsubsection{Labour market volatility}

Employment protection legislation: It is a standard result that, by increasing the cost of worker turnover, restrictions placed on hiring and firing (and the associated costs) are likely to reduce the flow of workers; the finding is often analytically derived from matching models (Mortensen and Pissarides, 1994). For instance, Blanchard and Portugal (2001) argue that, by increasing a firm's costs and workers' bargaining power, greater employment protection leads directly to lower layoffs and results in longer unemployment duration. The longer unemployment duration inhibits quits. Also, Pries and Rogerson (2005) find that, as it becomes more expensive to terminate matches, workers and firms need greater assurance that their match is a good one; firms find it less profitable to open new vacancies, and thus the flow of workers is lower.

Minimum wages: Consistent with search models with endogenous separations, minimum wage hikes have been found to have a negative effect on worker turnover, by reducing separations and accessions. Using data on teenage and restaurant workers in the US, Dube et al. (2016) find that turnover falls, affecting especially workers with lower tenure, a salient feature of young workers. Using Canadian data, Brochu and Green (2013) find that hires, quits and layoffs of low-skilled teenage workers fall as a result of a minimum wage hike. Portugal and Cardoso (2006) find that a selective rise in the minimum wage for teens in Portugal reduces worker turnover by reducing separations.

Unemployment insurance: Unemployment insurance (UI) or benefits schemes have two key features that may influence worker turnover: benefit level and potential benefit 
duration (Tatsiramos and van Ours, 2014). We focus on benefit level, as this is the data we have for the empirical analysis - which is unfortunate, since the empirical evidence shows that potential benefit duration has a larger impact on unemployment duration, and thus on exit rates to employment (Tatsiramos and van Ours, 2014). According to search theory, which has become the dominant approach to examining UI, benefit levels affect worker turnover through at least three channels, and have an ambiguous effect. First, since salaried work may provide entitlement to future UI, the so-called 'entitlement effect' increases the appeal of employment to those unemployed who do not qualify for benefits. This channel then increases turnover, by increasing accessions of individuals who do not qualify for benefits. The second channel has an ambiguous effect: higher benefit levels may induce insured and newly unemployed workers to increase their reservation wage, which reduces the possibility of them accepting a new job; but more generous benefits are also likely to promote a reduction in the reservation wages of unemployed workers who are close to benefit exhaustion, thus increasing exit rates from unemployment. The third channel brings about a turnover reduction. Higher benefit levels are likely to promote job matches of higher quality, higher productivity (Acemoglu and Shimer, 2000) and wages, and longer employment spells, which will in turn decrease turnover.

Labour market institutions have been usually studied one at a time, paying much less attention to the likely interactions that different institutions may have in determining outcomes. As Blanchard and Tirole (2008) argue, such interaction may be especially pertinent for unemployment insurance and employment protection. For instance, the negative effect of employment protection on accessions pointed out by Pries and Rogerson (2005) may be larger in the presence of low benefit levels, which induce workers to accept job matches of poorer quality. The likely negative effect of stricter employment protection legislation for temporary jobs may also depend on the generosity of the unemployment insurance, which allows (unemployed) workers to await better matches, possibly in terms of a permanent job.

The empirical evidence for continental European countries seems to suggest a positive effect of benefit levels on turnover. On the one hand, benefit levels are normally found to have a weak (or no) effect on exit rates from unemployment into employment in continental European countries (Holmlund, 1998; Tatsiramos and van Ours, 2014). In contrast, benefit levels are found to have a negative impact in the UK and the US, with a positive elasticity of unemployment duration with respect to benefit level lower than 1 and larger for the short-term unemployed. On the other hand, the level of benefits is found to have a significant positive effect on inflow into unemployment (Winter-Ebmer, 2003; Lalive and Zweimüller, 2004). Finally, Rebollo-Sanz (2012) finds the effects of unemployment insurance outlined above (i.e. longer unemployment spells and increased (employer-initiated) exit rates from employment) to be especially relevant for workers with a more marginal attachment to the labour market. She examines temporary workers and women, but much the same should apply to young workers.

Openness to trade: Trade openness has an ambiguous effect on job turnover and wage inequality (Coçar et al., 2016). On the one hand, it increases the sensitivity of a firm's revenues to its productivity and employment levels, which in turn increases job turnover. More successful firms are also likely to reap larger rents in more open economies, which widens the wage dispersion across firms. On the other hand, lower trade frictions make workers concentrate in larger, more stable firms, which tend to reduce turnover and wage inequality. Coçar et al. (2016) examine the impact of trade liberalization in Colombia in the 
1980s and find that the sensitivity effect dominates over the distributive effect, which implies higher turnover and larger earnings inequality.

Trade unions: In so far as trade unions are an effective means by which discontent workers may negotiate better conditions, they may reduce exit (which is the alternative way of escaping dissatisfaction). In other words, trade unions may provide a voice for workers, which may lead to a lower level of separations (Freeman, 1980). The higher wage pressure generally related to trade union presence is also likely to help reduce turnover. However, unionized firms have also been found to increase the use of layoffs by a) reducing quits and discharges, and b) by limiting the elasticity of wage (growth) and hours worked to changing demand conditions (Medoff, 1979; Dustmann and Schönberg, 2009). While the former may be regarded as a perfect substitute for layoffs and thus has no effect on overall separations, the latter leads to an increase in worker flow. The net effect is a priori ambiguous. Existing empirical evidence mostly provides support for the argument of negative union-density effects on turnover, as suggested by the voice hypothesis (e.g. Drago and Wooden, 1991 (Australia); Antcliff and Saundry, 2009 (UK); Hirsch et al., 2010; Lucifora, 1998 (Italy); or García-Serrano and Malo, 2002 (Spain)).

Active labour market programmes (ALMP): Youth employment is especially sensitive to economic fluctuations (Verick, 2011), and the most recent economic crisis has been no exception. According to Eurostat figures, the unemployment rate is substantially higher for youth than for adults - twice as high in some countries. ALMP seek a fast reintegration of unemployed workers into employment. Are they effective? Evidence from a recent meta-analysis points to positive (albeit limited) effects. In particular, job-search assistance and training programmes are generally found to have positive effects, though the latter mostly in the medium term. In contrast, public sector employment programmes are much less effective (Card et al., 2010). These findings seem to hold for the youth unemployed (Caliendo et al., 2011). Hence, ALMP may be expected to contribute to an increase in accessions and turnover.

\subsubsection{Earnings volatility}

Employment protection legislation: By increasing tenure, as well as the bargaining power of protected workers, stricter EPL is likely to reduce wage volatility. Given the lack of direct evidence of EPL on wage volatility, the most suggestive evidence comes from the indirect evidence through tenure. Conditional on employment, stricter EPL brings about longer tenure, which in turn has been found to have a negative effect on earnings instability in Italy (Cappellari and Leonardi, 2016).

Minimum wages: Higher minimum wages tend to compress wages at the lower end of the distribution (Holmlund, 2014; Autor et al., 2016). However, there is no theoretical or empirical guidance about their effect on earnings volatility. In the midst of the Great Recession, which characterizes our sample period, minimum wages most likely contributed to reduce earnings volatility by providing non-negative earnings growth rates at the lower end of the distribution, at least for those countries that opted to adjust the economy via prices rather than quantities.

Unemployment insurance: Unemployment insurance is unlikely to have a direct influence on earnings volatility, but it may do so by inducing job matches of higher quality and longer tenure, which will in turn decrease earnings instability (Cappellari and Leonardi, 2016). 
Openness to trade: As outlined above, trade openness is likely to increase wage inequality (Coçar et al., 2016). Traca (2005) also finds that trade liberalization brings about higher wage inequality.

Trade unions: Trade unions compress the wage distribution (Card, 1996; Lemieux, 1998; Card et al., 2004; Dustmann and Schönberg, 2009) and limit the capacity of firms to adjust to demand shocks through wage growth (Medoff, 1979; Dustmann and Schönberg, 2009). Hence, we expect earnings volatility to be lower in more unionized countries.

Active labour market programmes: We do not have theoretical insights to foresee the effect of ALMP on individual wage growth variability, and empirical studies so far have not paid much attention to the impact on wages, let alone wage growth and its variability (Card et al., 2010).

\subsection{Data on institutions}

In order to examine the relationship between institutional features and our volatility estimates at the country level (Section 4), we gathered information from different sources on salient features of the six institutions referred to above, as well as data on other controls, i.e. GDP, unemployment rate and NEET, for the 28 European countries over the nine years covered by our sample period (2005-2013). Next, we briefly describe each variable.

EPL includes many provisions that regulate both monetary and non-monetary aspects of hiring and firing for both permanent and temporary jobs. To capture the most salient of these aspects, we use the OECD composite index of employment protection regulation of temporary contracts, a score measured on a scale of $0-6$, with higher values representing stricter regulation; this builds on eight items and considers the regulation of fixed-term contracts and of temporary work agencies.

Our measure of minimum wages is the commonly used minimum relative to the median wage of full-time workers, as reported by the OECD.

Unemployment insurance or benefit schemes have two key features that may influence volatility: benefit level and potential benefit duration. Given the lack of harmonized and consistent data on potential benefit duration, we use information on benefit levels. In particular, our variable is the unemployment insurance replacement rate (UIRR). Effective replacement rates depend on personal and household characteristics. We use OECD estimates for a single person with no children and average worker earnings.

To capture openness to trade, we use Dreher's (2006) index of actual flow, which measures trade liberalization through realized outcomes, instead of using other aspects of trade openness, such as legal and economic restrictions and barriers (e.g. tariffs). This measure is a weighted sum of four components (all expressed as a percentage of GDP): trade, foreign direct investment, portfolio investment and income payments to foreign nationals. The index ranges from 0 (null openness) to 10 (complete openness).

Trade union density corresponds to the ratio of wage and salary earners that are trade union members, divided by the total number of wage and salary earners, as taken from the OECD Labour Force Statistics.

The variable on active labour market programmes is expenditure on ALM programmes, expressed as a percentage of GDP, as reported by the OECD. It includes expenditure on placement and administration, training, employment incentives, sheltered and supported employment and rehabilitation, direct job creation and start-up incentives. We do not use passive labour market policies, as they include programmes that are not so relevant 
for the youth, such as expenditure on early retirement.

Finally, our control variables - i.e. the proportion of 15-29-year-olds who are NEET, GDP and the unemployment rate - are also drawn from the OECD.

Due to limited data availability, we have an unbalanced panel, since we lack some institutional data for certain years and countries. The countries for which the lack of data is more severe include some Eastern European countries, such as Bulgaria, Romania and Lithuania, but also Cyprus and Malta.

To gain a first insight about the raw impact of each of the institutional features, Table 1 reports coefficient estimates of separate fixed-effect regressions of labour market and earnings volatility on each variable, year dummies and a constant term.

According to the simple correlations, three institutions show a significant and negative effect on youth earnings volatility. The negative relationship between UIRR and earnings volatility is consistent with benefit levels inducing job matches of higher quality and longer tenure. The negative association with the strictness of EPL (of temporary and permanent jobs, the latter not displayed) is also consistent with longer tenures that are brought about by stricter EPL. ALMP, for which we do not have any prior hypothesis, also correlate negatively with earnings volatility. Turning to the control variables, earnings volatility shows a positive correlation with the unemployment rate, as well as with the proportion of youth NEET.

The same three institutions that correlate with earnings volatility also correlate, and with the same sign, with labour market volatility. Contrary to what we found for earnings volatility, though, now trade openness shows a positive link to labour market volatility. This finding is consistent with the empirical evidence for Colombia provided by Coçar et al. (2016), and suggests a sensitivity effect that dominates over the distributive effect.

Table 1: Raw effect of institutions and controls on volatility, 2005-2013

\begin{tabular}{|l|l|l|l|l|l|}
\hline & $\begin{array}{l}\text { Earnings } \\
\text { volatility }\end{array}$ & & $\begin{array}{l}\text { Labour } \\
\text { market } \\
\text { volatility }\end{array}$ & & $N$ \\
\hline GDP per capita & -0.0001 & & -0.0006 & $* * *$ & 225 \\
\hline GDP growth & 0.1475 & & 0.2817 & $*$ & 225 \\
\hline Unemployment rate & 0.5567 & $* * *$ & 0.8058 & $* * *$ & 225 \\
\hline NEET & 0.3213 & $*$ & 0.7926 & $* * *$ & 225 \\
\hline UI replacement rates & -0.2443 & $* * *$ & -0.2250 & $* * *$ & 218 \\
\hline Trade openness & 0.1717 & & 0.4160 & $* *$ & 200 \\
\hline Trade union density & -0.2354 & & 0.0622 & & 178 \\
\hline EPL temporary & -7.8859 & $* * *$ & -11.4620 & $* * *$ & 174 \\
\hline ALMP & -32.5857 & $* *$ & -57.6533 & $* * *$ & 169 \\
\hline Minimum wage & 5.9937 & & -13.1082 & & 142 \\
\hline
\end{tabular}

Note: Each row reports the coefficient estimate of a separate fixed-effect regression that also includes year dummies and constant term. $* * *$ significant at $1 \%$; ** at $5 \%$; $*$ at $10 \%$. 


\subsection{What institutions account for volatility?}

The simple correlations of Table 1 ignore possible correlation among variables that capture relevant aspects of the institutional setting, and between these institutional variables and other controls. Table 2 reports coefficient estimates of a fixed-effect regression that includes a set of institutional variables, $N$, a set of controls, $X$, and year dummies, $t$ :

$$
l_{i t}=\alpha+N_{i t}^{\prime} \beta+X_{i t}^{\prime} \gamma+t^{\prime} \tau+\varepsilon_{i}+v_{i t}
$$

where the vector $\beta$ collects our parameters of interest, $\varepsilon_{i}$ denotes the country fixed effect, and $v_{i t}$ is an independent and identically distributed error term.

Column (1) in Table 2 is concerned with youth earnings volatility. It presents the results of our preferred model, which includes the variables that show a statistically significant raw correlation in Table $1 .^{3}$ Two institutions seem to be associated with earnings volatility: unemployment insurance and employment protection legislation. As suggested in Section 5.1, our findings corroborate the importance of the possible interaction between these two institutions. Thus, the effect of either of the institutions on earnings volatility depends on the value of the other variable. Since the estimated coefficients of UI and EPL are positive and the estimated coefficient of the interaction term is negative, the impact of either institution will be positive for sufficiently low values of the other variable, while it will be negative for sufficiently high values of the other variable. That is, the effect of the two institutions offset each other. In particular, the degree of generosity of unemployment insurance has a negative effect on earnings volatility for levels of EPL higher than 1.275 (recall that the EPL variable takes values from 0 to 6), which corresponds to the 28th percentile of the EPL distribution in our sample. Stricter EPL also has a negative effect on earnings volatility for unemployment insurance replacement rates higher than $49.6 \%$, which corresponds to the 10th percentile of the sample distribution. Therefore, both variables correlate negatively with earnings volatility for most of the support. As outlined above, the negative relationship between these two variables and earnings volatility is consistent with benefit levels and strict EPL inducing job matches of higher quality and longer tenure, which in turn reduces earnings volatility.

It is also worth noting that while earnings volatility increases with the unemployment rate for the whole population, it is not sensitive to changes in the percentage of youth who are not in employment, education or training.

Columns (2) and (3) of Table 2 refer to labour market volatility. Column (2) displays the estimates of a specification that includes variables that show statistically significant raw correlations with labour market volatility in Table 1, while our preferred model in column (3) keeps the significant covariates from the previous column and shows that estimates are stable to the excluded variables and to the slight change in sample size that this exclusion implies. Estimates in column (3) tell a story analogous to that of earnings volatility: only unemployment insurance and employment protection legislation seem to matter for labour market volatility; the interaction of the two institutions is also important; and the relationship between the two institutions, on the one hand, and labour market volatility, on the other, is negative for the greater part of the support - the degree of generosity of unemployment insurance has a negative effect on earnings volatility for levels of EPL higher than 1.20, 
which corresponds to the 29th percentile of the EPL distribution in our sample, while stricter EPL also has a negative effect on earnings volatility for UIRR higher than $47.8 \%$, which corresponds to the 14th percentile of the sample distribution. Comparing Spain and the Netherlands provides a good illustration about how the interaction between EPL and UIRR work. Spain displays large earnings and labour market volatility. Her large unemployment insurance replacement rates, about 60 per cent, and the strict employment protection legislation, which include large dismissal costs for permanent workers and lead to a dual labour market, are partly responsible for this. The Netherlands, instead displays much lower earnings and labour market volatility. Her unemployment insurance is more generous than that of the Spanish system, about 10 per cent more, but employment protection is also much laxer. The negative effect of the interaction between employment protection and unemployment insurance implies that increasing the generosity of the Spanish unemployment insurance to Dutch levels would decrease volatility, as presumably (unemployed) workers would have the opportunity to search for better job matches.

Unlike earnings volatility, labour market volatility decreases as GDP per capita grows.

Conditional on all the other covariates, year effects show a U-shaped pattern, with a minimum in 2009. This indicates that the Great Recession increased volatility among Europe's youth, offsetting the falling trend observed over the last years of economic prosperity.

Table 2: What accounts for earnings and labour market volatility, 2005-2013

\begin{tabular}{|c|c|c|c|c|c|c|c|c|c|}
\hline & \multirow{2}{*}{\multicolumn{3}{|c|}{$\begin{array}{c}\text { Earnings volatility } \\
\text { (1) }\end{array}$}} & \multicolumn{6}{|c|}{ Labour market volatility } \\
\hline & & & & \multicolumn{3}{|c|}{ (2) } & \multicolumn{3}{|c|}{ (3) } \\
\hline & & & Std. Err & & & Std. Err. & & & Std. Err. \\
\hline GDP per capita & & & & -0.0004 & * & 0.0002 & -0.0004 & ** & 0.0002 \\
\hline GDP growth & & & & 0.07 & & 0.21 & & & \\
\hline Unemployment rate & 0.68 & *** & 0.28 & 0.36 & & 0.41 & & & \\
\hline NEET & -0.37 & & 0.34 & -0.0002 & & 0.50 & & & \\
\hline UI replacement rates & 0.43 & **** & 0.17 & 0.90 & **** & 0.24 & 0.73 & *** $*$ & 0.22 \\
\hline ALMP & -4.02 & & 14.33 & -15.00 & & 21.63 & & & \\
\hline EPL temporary & 16.05 & **** & 7.03 & 40.41 & **** & 10.93 & 28.25 & **** & 8.76 \\
\hline Trade openness & & & & -0.37 & & 0.27 & & & \\
\hline UIRR*EPL Temp & -0.34 & **** & 0.11 & -0.79 & **** & 0.17 & -0.61 & *** $*$ & 0.14 \\
\hline Year & & & & & & & & & \\
\hline 2006 & -1.87 & & 1.36 & 0.12 & & 1.99 & -1.16 & & 1.91 \\
\hline 2007 & -3.08 & *** & 1.43 & -1.94 & & 2.36 & -3.62 & * & 2.08 \\
\hline 2008 & -3.20 & *** & 1.35 & -2.64 & & 2.25 & -4.30 & ** & 1.97 \\
\hline 2009 & -3.72 & **** & 1.35 & -4.14 & * & 2.52 & -4.94 & **** & 1.84 \\
\hline 2010 & -3.24 & *** & 1.38 & -2.31 & & 2.26 & -3.60 & * & 1.95 \\
\hline 2011 & -2.88 & $* *$ & 1.36 & 1.88 & & 2.24 & 1.63 & & 1.99 \\
\hline 2012 & -2.55 & * & 1.39 & 0.30 & & 2.68 & 0.26 & & 2.04 \\
\hline 2013 & -2.04 & & 1.45 & & & & -0.79 & & 2.07 \\
\hline Constant & 39.43 & **** & 11.13 & 81.43 & *** & 27.82 & 65.22 & *** & 14.23 \\
\hline$N$ & & & & & 14 & & & 17 & \\
\hline
\end{tabular}




\section{Conclusions}

This paper studies youth earnings and labour market volatility across 28 European countries for the period 2004-2013. Using data from the EU-SILC on young people between the ages of 17 and 29, we compute the standard deviation of the arc percentage change in individual earnings between $t-1$ and $t$. This index measures earnings volatility when only year-to-year changes in positive wages are considered, and also labour market volatility if we include zero wages, i.e. transitions into and out of employment.

Our findings show large disparities in youth earnings, and especially labour market volatility levels and trends across European countries; this does not allow us to group countries into clusters. As might be expected, the Great Recession increases volatility among Europe's youth, offsetting the falling trend observed during the period of economic prosperity. Volatility is found not to differ across certain characteristics, such as gender, age or education.

To what extent is overall labour market volatility due to earnings changes and to worker flows into and out of employment? A variance decomposition exercise reveals that earnings changes account for a large share of overall labour market volatility in Northern Europe. By contrast, employment flows are most relevant in Southern Europe. This suggests that a one-size policy does not fit all. Instead, different policies are required to address the differential nature of labour market volatility in different European regions. Also notice that the different nature of labour market volatility is consistent with the ways in which different labour markets adjusted to the shocks that came with the Great Recession.

Our analysis of the influence of the most relevant labour market institutions on volatility singles out unemployment insurance and employment protection legislation. Our interpretation is that these institutions contribute to reducing volatility by increasing the quality of job matches. Accomplishing good job matches is complex, in so far as it is unlikely to be fully achieved by demand- or supply-side policies alone - the fact that volatility does not differ across education levels seems to bear this out. Rather, it calls for a balanced mix of supply- and demand-type policies. If, as we assume, job matches are important, this means that heterogeneity is relevant, and this has implications both for scholarly research and for policy making.

Our paper has several limitations. On the one hand, we were not able to determine how much of the earnings shocks translate into economic risk. Such link will necessarily depend on the tax and transfer system at place in each country and also the extent to which young people can rely on intra-household transfers to buffer the impact of earnings changes. For example, Venn (2011) establishes that while household disposable income is buffered from the full impact of individual earnings volatility in most countries, it is particularly strong in the Northern Europe while particularly weak in Mediterranean Europe. The author estimates that the change in total household income is on average only $30 \%$ of the size of a decrease in individual earnings. In Portugal, Spain or Italy, the same figure is on average 66\%. Moreover, and as argued by Blundell et al. (2008) and Cunha et al. (2005), one requires more information to assess whether changes were anticipated or chosen, and whether they were insured against or not. In our paper, however, as we refer to young people, and given the context of the Great Recession, it is unlikely that such changes were a matter of choice for young people. On the other hand, this paper is about changes in the labour market and therefore ignores the situation of young people who are continuously unemployed - possibly 
those who have suffered most from the Great Recession.

\section{Notes}

[1] The empirical analysis of a sample that includes students yields similar results. The most significant change is that labour market volatility shows higher levels; trends, however, remain largely unchanged. We find no significant differences for earnings volatility. Finally, as we find for the sample without students, only the generosity of unemployment insurance and employment protection legislation account for earnings and labour market volatility. All the evidence is available from the authors on request.

[2] Of course, if the unobserved heterogeneity, which drives attrition, has a time-varying component, first differences will not eliminate the bias. Furthermore, the size and direction of the potential bias is difficult to gauge. In their analysis of the attrition effects on poverty persistence rates in the EU-SILC data, Jenkins and Van Kerm (2017) conclude that there is substantial cross-national diversity in the characteristics of individuals lost to follow-up, and that the assumptions about the poverty status of those lost to attrition have an important influence on estimates for most countries. A full assessment of attrition bias and its implications in the EU-SILC is beyond the scope of this paper.

[3] These results are robust to including the two GDP-related variables, which are also included in column (2) for labour market volatility. The large coefficients on EPL and ALMP are due to the scaling of those variables.

[4] Other specifications provide the same evidence. For instance, the U-shaped pattern of year dummies is also obtained from (i) a regression with time dummies only, and no covariates; (ii) a regression with the year variable entered linear and squared; and (iii) a regression where the linear year variable is interacted with a post-recession dummy, taking value 1 for the post-recession years.

\section{References}

Acemoglu, D., and R. Shimer (2000): 'Productivity gains from unemployment insurance', European Economic Review, 44(7), 1195-1224.

Antcliff, V., and R. Saundry (2009): 'Accompaniment, workplace representation and disciplinary outcomes in British workplaces just a formality?', British Journal of Industrial Relations, 47(1), 100-121.

Autor, D., A. Manning, and C. Smith (2016): 'The contribution of the minimum wage to US wage inequality over three decades: A reassessment', American Economic Journal: Applied Economics, 8(1), 58-99.

Baker, M., and G. Solon (2003): 'Earnings dynamics and inequality among Canadian men, 1976-1992: Evidence from longitudinal income tax records', Journal of Labor Economics, 21, 289-321. 
Becker, G.S., E.M. Landes, and R.T. Michael (1977): 'An economic analysis of marital instability', Journal of Political Economy, 85(6), 1141-1187.

Becker, S.O., S. Bentolila, A. Fernandes, and A. Ichino (2010): 'Youth emancipation and perceived job insecurity of parents and children', Journal of Population Economics, 23(3), 1047-1071.

Blanchard, O., and P. Portugal (2001): 'What hides behind an unemployment rate: Comparing Portuguese and US Labor Markets', American Economic Review, 91(1), 187-207.

Blanchard, O., and J. Tirole (2008): 'The joint design of unemployment insurance and employment protection: a first pass', Journal of the European Economic Association, 6, 45-77.

Blundell, R., L. Pistaferri, and I. Preston (2008): 'Consumption inequality and partial insurance', American Economic Review, 98, 1887-1921.

Breen, R., and P. Moisio (2004): 'Poverty dynamics corrected for measurement error', Journal of Economic Inequality, 2, 171-191.

Brochu, P., and D. Green (2013): 'The Impact of minimum wages on labor market transitions', Economic Journal, 123, 1203-1235.

Caliendo, M., S. Künn, and R. Schmidt (2011): 'Fighting youth unemployment: The effects of active labor market policies', Discussion Paper 6222, IZA.

Cappellari, L., and S.P. Jenkins (2014): 'Earnings and labour market volatility in Britain, with a transatlantic comparison', Labour Economics, 30(C), 201-211.

Cappellari, L., and M. Leonardi (2016): 'Earnings instability and tenure', The Scandinavian Journal of Economics, 118(2), 202-234.

Card, D. (1996): 'The effect of unions on the structure of wages: A longitudinal analysis', Econometrica, 64(4), 957-979.

Card, D., J. Kluve, and A. Weber (2010): 'Active labour market policy evaluations: A meta-analysis’, Economic Journal, 120, F452-F477.

Card, D., T. Lemieux, and W. Riddell (2004): 'Unions and wage inequality', Journal of Labor Research, 25(4), 519-562.

Caroli, E., and M. Godard (2016): 'Does job insecurity deteriorate health?', Health Economics, 25(2), 131-147.

Clark, A., P. Frijters, and A. Shields (2008): 'Relative income, happiness, and utility: An 
explanation for the Easterlin Paradox and other puzzles', Journal of Economic Literature, 46(1), 95-144.

Coçar, A.K., N. Guner, and J. Tybout (2016): 'Firm dynamics, job turnover, and wage distributions in an open economy', American Economic Review, 106(3), 625-663.

Cunha, F., J. Heckman, and S. Navarro (2005): 'Separating uncertainty from heterogeneity in life cycle earnings', Oxford Economic Papers, 57, 191-261.

Daly, M.C., and R.G. Valletta (2008): 'Cross-national trends in earnings inequality and instability', Economics Letters, 99(2), 215-219.

De la Rica, S. (2005): 'Career planning in Spain: Do fixed-term contracts delay marriage and parenthood?', Review of Economics of the Household, 3, 49-73.

Del Bono, E., A. Weber, and R. Winter-Ebmer (2012): 'Clash of career and family: Fertility decisions after job displacement', Journal of the European Economic Association, 10(4), 659-683.

Del Bono, E., A. Weber, and R. Winter-Ebmer (2015): 'Fertility and economic instability: the role of unemployment and job displacement', Journal of Population Economics, 28(2), 463-478.

Drago, R., and M. Wooden (1991): 'Turnover Down Under: Trade unions and exit behaviour in Australia', Journal of Industrial Relations, 33(2), 234-248.

Dreher, A. (2006): 'Does globalization affect growth? Evidence from a new index of globalization', Applied Economics, 38(10), 1091-1110.

Dube, A., T. Lester, and M. Reich (2016): 'Minimum wage shocks, employment flows, and labor market frictions', Journal of Labor Economics, 34(3), 663-704.

Dustmann, C., and U. Schönberg (2009): 'Training and union wages', Review of Economics and Statistics, 91(2), 363-376.

Dynan, K., D. Elmendorf, and D. Sichel (2012): 'The evolution of household income volatility', The B.E. Journal of Economic Analysis \& Policy, 12(2), 1-42.

Freeman, R. (1980): 'The exit-voice tradeoff in the labor market: Unionism, job tenure, quits, and separations', Quarterly Journal of Economics, 94, 43-63.

García-Serrano, C., and M. Malo (2002): 'Worker turnover, job turnover and collective bargaining in Spain', British Journal of Industrial Relations, 40(1), 69-85.

Guiso, L., and T. Jappelli (1992): 'Earnings uncertainty and precautionary saving', Journal of Monetary Economics, 30(2), 307-337. 
Haurin, D. R. (1991): 'Income variability, homeownership, and housing demand', Journal of Housing Economics, 29(2), 219-229.

Hirsch, B., T. Schank, and C. Schnabel (2010): 'Works councils and separations: Voice, monopoly, and insurance effects', Industrial Relations, 49(4), 566-592.

Holmlund, B. (1998): 'Unemployment insurance in theory and practice', Scandinavian Journal of Economics, 100, 113-141.

Holmlund, B. (2014): 'What do labor market institutions do?', Labour Economics, 30, 62-69.

Iacovou, M., and P. Lynn (2013): 'Implications of the EU-SILC following rules, and they implementation for longitudinal analysis', Discussion Paper 2013-17, Institute for Economic and Social Research.

Jenkins, S., and P. V. Kerm (2017): 'How does attrition affect estimates of persistent poverty rates?', Statistical Working Papers, Eurostat.

Kodde, D. A. (1986): 'Uncertainty and the demand for education', Review of Economic and Statistics, 68(3), 460-467.

Krell, K., J. R. Frick, and M. Grabka (2017): 'Measuring the consistency of cross-sectional and longitudinal income information in EU-SILC', Review of Income and Wealth, 63(1), $30-52$.

Lalive, R., and J. Zweimüller (2004): 'Benefit entitlement and the labor market: Evidence from a large-scale policy change', in Labor Market Institutions and Public Policy, ed. by J. Agell, M. Keene, and A. Weichenrieder. MIT Press.

Lemieux, T. (1998): 'Estimating the effects of unions on wage inequality in a panel data model with comparative advantage and nonrandom selection', Journal of Labor Economics, 16(2), 261-291.

Lillard, L., and R. Willis (1978): 'Dynamic aspects of earnings mobility', Econometrica, 46, 985-1012.

Lucifora, C. (1998): 'The impact of unions on labour turnover in Italy: Evidence from establishment level data', International Journal of Industrial Organization, 16(3), 353-376.

Matsudaira, J.D. (2016): 'Economic conditions and the living arrangements of young adults: 1960 to 2011', Journal of Population Economics, 29(1), 167-195.

Medoff, J. (1979): 'Layoffs and alternatives under trade unions in US manufacturing', American Economic Review, 69(3), 380-395.

Meghir, C., and L. Pistaferri (2011): 'Earnings, consumption and life cycle choices', in 
Handbook of Labor Economics, Vol. 4B, ed. by O. Ashenfelter, and D. Card. Elsevier.

Mortensen, D.T., and C. Pissarides (1994): 'Job creation and job destruction in the theory of unemployment', Review of Economic Studies, 61, 397-415.

Portugal, P., and A. Cardoso (2006): 'Disentangling the minimum wage puzzle: An analysis of worker accessions and separations', Journal of the European Economic Association, 4(5), 988-1013.

Pries, M., and R. Rogerson (2005): 'Hiring policies, labor market institutions and labor market flows', Journal of Political Economy, 113(4), 811-839.

Rebollo-Sanz, Y. (2012): 'Unemployment insurance and job turnover in Spain', Labour Economics, 19, 403-426.

Shin, D. (2012): 'Recent trends in men's earnings volatility: Evidence from the National Longitudinal Survey of Youth, 1985-2009', The B.E. Journal of Economic Analysis \& Policy, 12(2), 1-13.

Shin, D., and G. Solon (2008): 'Trends in men's earnings volatility: What does the Panel Study of Income Dynamics show?', NBER Working Papers 14075.

Shin, D., and G. Solon (2011): 'Trends in men's earnings volatility: What does the Panel Study of Income Dynamics show?', Journal of Public Economics, 95(7-8), 973-982.

Snow, A., and R.S. Warren (1990): 'Human capital investment and labor supply under uncertainty', International Economic Review, 31(1), 195-206.

Sologon, D.M., and C. O’Donoghue (2014): 'Shaping earnings insecurity: Labor market policy and institutional factors', Review of Income and Wealth, 60, S205-S232.

Tatsiramos, K., and J.C. van Ours (2014): 'Labor market effects of unemployment insurance design', Journal of Economic Surveys, 28(2), 284-311.

Traca, T.A. (2005): 'Globalization, wage volatility, and the welfare of workers', Review of International Economics, 13(2), 237-249.

Venn, D. (2011): 'Earnings volatility and its consequences for households', Discussion paper, OECD Social, Employment and Migration Working Papers No. 125.

Verick, S. (2011): 'Who is hit hardest during a financial crisis? The vulnerability of young men and women to unemployment in an economic downturn', in From the Great Recession to Labour Market Recovery: Issues, evidence and policy options, ed. by I. Islam. ILO/Palgrave Macmillan.

Winter-Ebmer, R. (2003): 'Benefit duration and unemployment entry: Quasi-experimental evidence for Austria’, European Economic Review, 47, 259-273. 
Ziliak, J.P., B. Hardy, and C. Bollinger (2011): 'Earnings volatility in America: Evidence from matched CPS', Labour Economics, 18(6), 742-754. 